\title{
The Effect of Kinesio Taping on the Reduction of Pain in Patients with Carpal Tunnel Syndrome: Meta-Analysis
}

\author{
Cahyo Setiawan'), Didik Gunawan Tamtomo'), Hanung Prasetya') \\ 1)Masters Program in Public Health, Universitas Sebelas Maret, Surakarta \\ ${ }^{2)}$ Study Program of Acupuncture, Health Polytechnics Ministry of Health Surakarta
}

\section{ABSTRACT}

Background: Carpal tunnel syndrome (CTS) is the most common occurrence of nerve compression. Some cases of CTS have chronic symptoms. The most common complaint is "Nocturnal Acroparesthesia", which is tingling pain at night. Physiotherapy interventions can be done to relieve complaints of CTS one of which is the use of Kinesio Taping. This study aimed to analyze the effect of Kinesio taping on the reduction of pain in patients with carpal tunnel syndrome from some previous studies.

Subjects and Method: This was a systematic and meta-analysis study. The study used the PICO model as follows Population=Patients with Carpal Tunnel Syndrome, Intervention= Given Kinesio Taping, Comparison= Not Given Kinesio Taping, and Outcome=Reductionof $\mathrm{Pa}-$ in. The articles used in this study were obtained from several databases including PubMed, ScienceDirect, and Google Scholar. The articles were collected in a month. The keywords for searching the articles were as follows: "kinesio taping" OR "kinesio tape" OR "pain" OR "carpal tunnel syndrome" AND "Randomized Controlled Trial". The articles included in this study were full-text articles with a randomized controlled trial study design. The articles were collected using PRISMA flow diagrams and analyzed using the Review Manager 5.3 application.

Results: The total of seven articles reviewed in this meta-analysis study was from Turkey, Poland, the Republic of Korea, Egypt, and the USA. The studies showed that giving KT could reduce pain in CTS and it was statistically very significant (Standardized Mean Difference $=$ $1.21 ; 95 \% \mathrm{CI}=-2.14$ to $-0.28 ; \mathrm{p}<0.01)$.

Conclusion: Kinesio Taping can reduce pain in Carpal Tunnel Syndrome.

Keywords: kinesio taping, reduction of pain, carpal tunnel syndrome.

\section{Correspondence:}

Cahyo Setiawan, Masters Program In Public Health, Sebelas Maret University, Jl. Ir. Sutami 36A, Surakarta 57126, Central Java, Indonesia. Email: setiawan.cahyo10@gmail.com.Mobile Phone: 089693257305.

\section{Cite this as:}

Setiawan C, Tamtomo DG, Prasetya H (Year). The Effect of Kinesio Taping on the Reduction of Pain in Patients with Carpal Tunnel Syndrome: Meta-Analysis. Indones J Med. 06(01): 104-111. https://doi.org/10.26911/theijmed.2021.06.01.11.

cC) (1) Indonesian Journal of Medicine is licensed under a Creative Commons cc)

\section{BACKGROUND}

Carpal tunnel syndrome (CTS) is the most common occurrence of nerve compression. CTS is included in the group of entrapment neuropathy or compression neuropathy which is commonly found and it is also included in Cumulative Trauma Disorders (CTDs) (Karabay, 2013).
As one of the three most common types of disease in the upper limb CTDs class, it was found that the prevalence in CTS cases was 40\%, while in Trigger Finger cases $32 \%$, De Quervan's Syndrome 12\% and epicondylitis 20\% (Ibrahim, 2012).

According to Newington et al., (2015), carpal tunnel syndrome was more common in women with an annual incidence of 1.5 
per 1000 and 0.5 per 1000 in men. The peak incidence in women occurred at age 45 years. In Indonesia, the prevalence of CTS was between $5.6 \%$ to $15 \%$ (Azizah et al., 2020).

There are several treatments for people with CTS that can be categorized as operative and non-operative. The non-operative method is effective in patients with mild to moderate CTS with indications of no muscle weakness, atrophy, or nerve denervation (Kosery et al., 2012).

Furthermore, to relieve complaints of CTS, physiotherapy interventions could also be carried out by using Kinesio Taping, Electrical Stimulation, etc. (Ardella, 2013).

A study conducted by Kosery et al., (2012) presented that Kinesio taping was very effective, efficient, cheap, light, safe, and harmless in the case of CTS. The elastic properties of Kinesio taping also created gentle massage with movement, changes in pressure and movement of the skin could open and close the initial lymphatic vessels, and Kinesio taping on the lymphatic surface could stimulate edema movement, the reduction of edema removed heat and chemicals in the tissue, improved circulation and reduced trigger points (Ardella, 2013).

Kinesio taping is an intervention that functions for muscle facilitation, inhibition, improves lymphatic flow, and reduces pain. The therapeutic effect of Kinesio taping is caused by the interaction between stimulation of afferents on the skin and motor units of the Central Nervous System and the Peripheral Nervous System which can stimulate cutaneous mechanoreceptors (Cai et al., 2016).

Based on the high incidence of CTS and the use of Kinesio taping to reduce pain in patients with CTS, the researchers were interested in examining the effect of kinesio taping on the reduction of pain in patients with carpal tunnel syndrome. The data ob- tained were analyzed using systematic review and meta-analysis as an effort to obtain comprehensive results, by synthesizing the results of primary studies involving Kinesio taping to reduce pain in patients with carpal tunnel syndrome.

\section{SUBJECTS AND METHOD}

\section{Study Design}

This was a systematic and meta-analysis study. The articles used in this study were obtained from several databases including PubMed, ScienceDirect, and Google Scholar. The keywords for searching articles were as follows: "kinesio taping" OR "kinesio tape" OR "pain" OR "carpal tunnel syndrome" AND "Randomized Controlled Trial".

\section{Inclusion Criteria}

The articles included in this study were full paper articles with randomized controlled trial study designs. The subjects of the study were patients with carpal tunnel syndrome. The selected article discussed the Effect of Kinesio Taping on the Reduction of Pain in Patients with Carpal Tunnel Syndrome.

\section{Exclusion Criteria}

The articles were excluded from this study were articles with non-RCT study designs, non-full text articles, articles published before 2005, and non-English articles.

\section{Operational Definition of Variables}

The article search was carried out by considering the eligibility criteria defined using the PICO model. The population in this study was patients with Carpal Tunnel Syndrome, with an intervention in the form of Kinesio Taping, a comparison which was not given Kinesio Taping, and the outcome was the reduction of pain.

The administration of Kinesio Tape functioned to facilitate muscle, inhibition, improve lymphatic flow, and reduce pain, especially in patients with CTS. Instrument: 
VAS (Visual Analog Scale) with a categorical measuring scale.

\section{Data Analysis}

Data processing was carried out by a Review Manager (RevMan 5.3) by calculating the mean difference to determine the research model that was combined and to form the final meta-analysis result.

\section{RESULTS}

The process of searching for articles was through a database with journals can be seen in Figure 1.Figure 2 shows the areas where articles were drawn according to the inclusion criteria. The articles were obtained from 4 continents, namely America, Europe, Africa, and Asia.

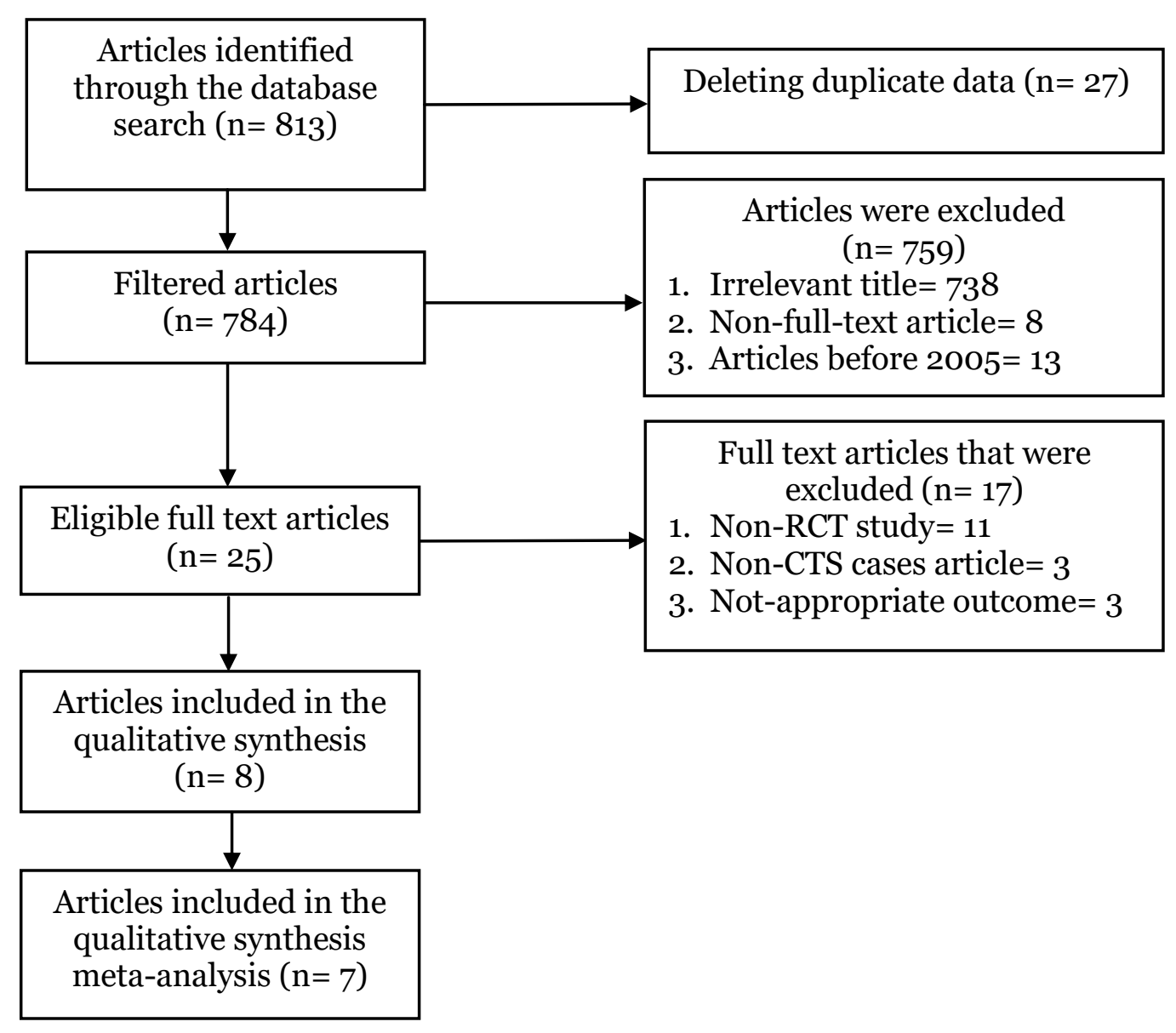

Figure 1. PRISMA flow diagram 
Setiawan et al./ The Effect of Kinesio Taping on Pain in Patients with Carpal Tunnel Syndrome

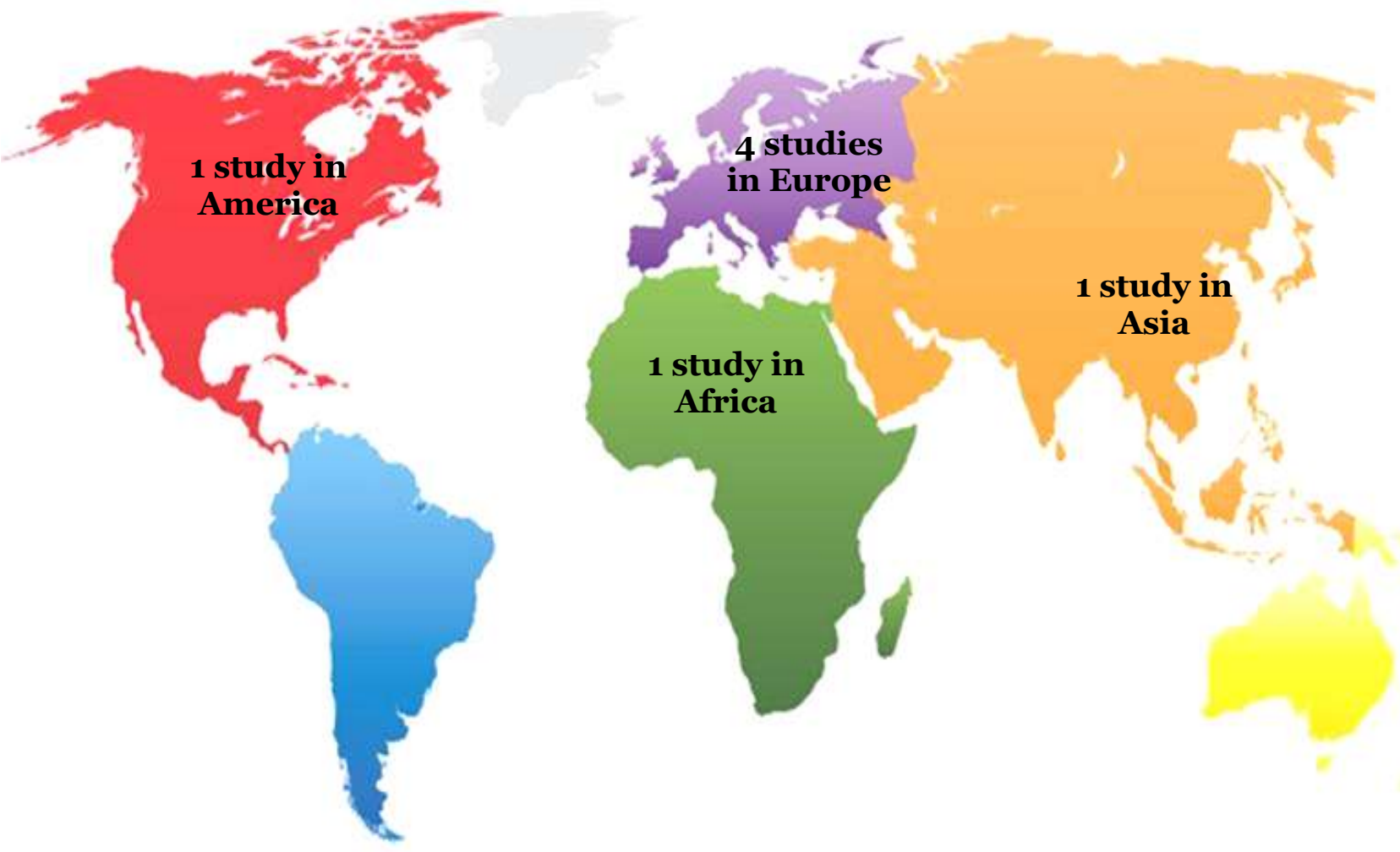

Figure 2. Map of area distribution

\section{A. Forest plot}

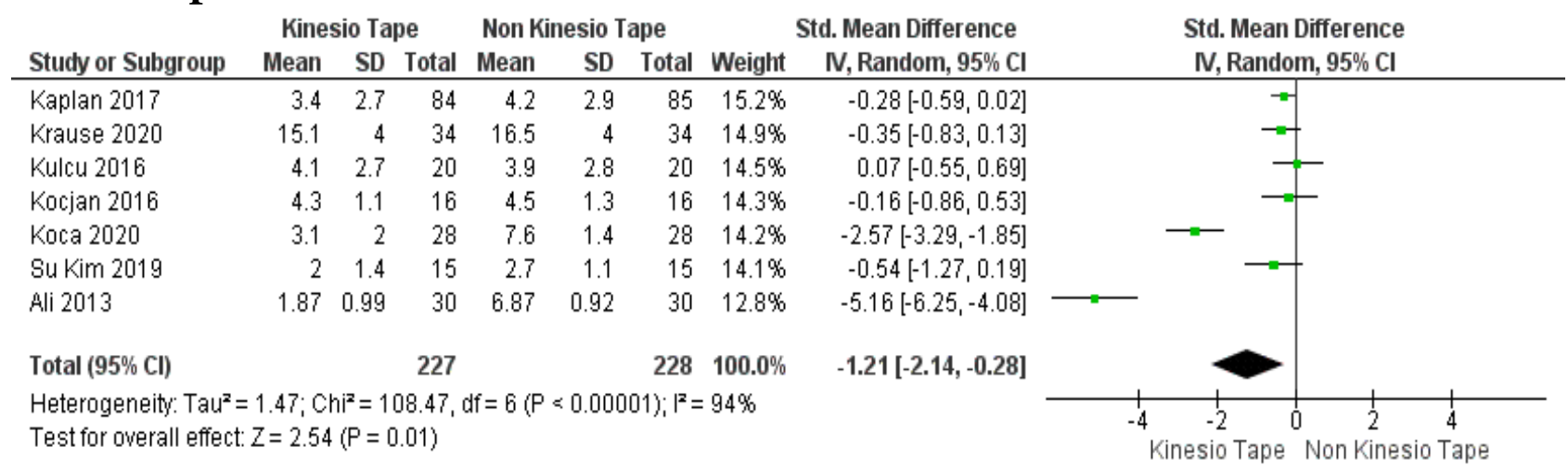

Figure 3. Forest plot of the effect of kinesio tape on the reduction of pain in patients with carpal tunnel syndrome 


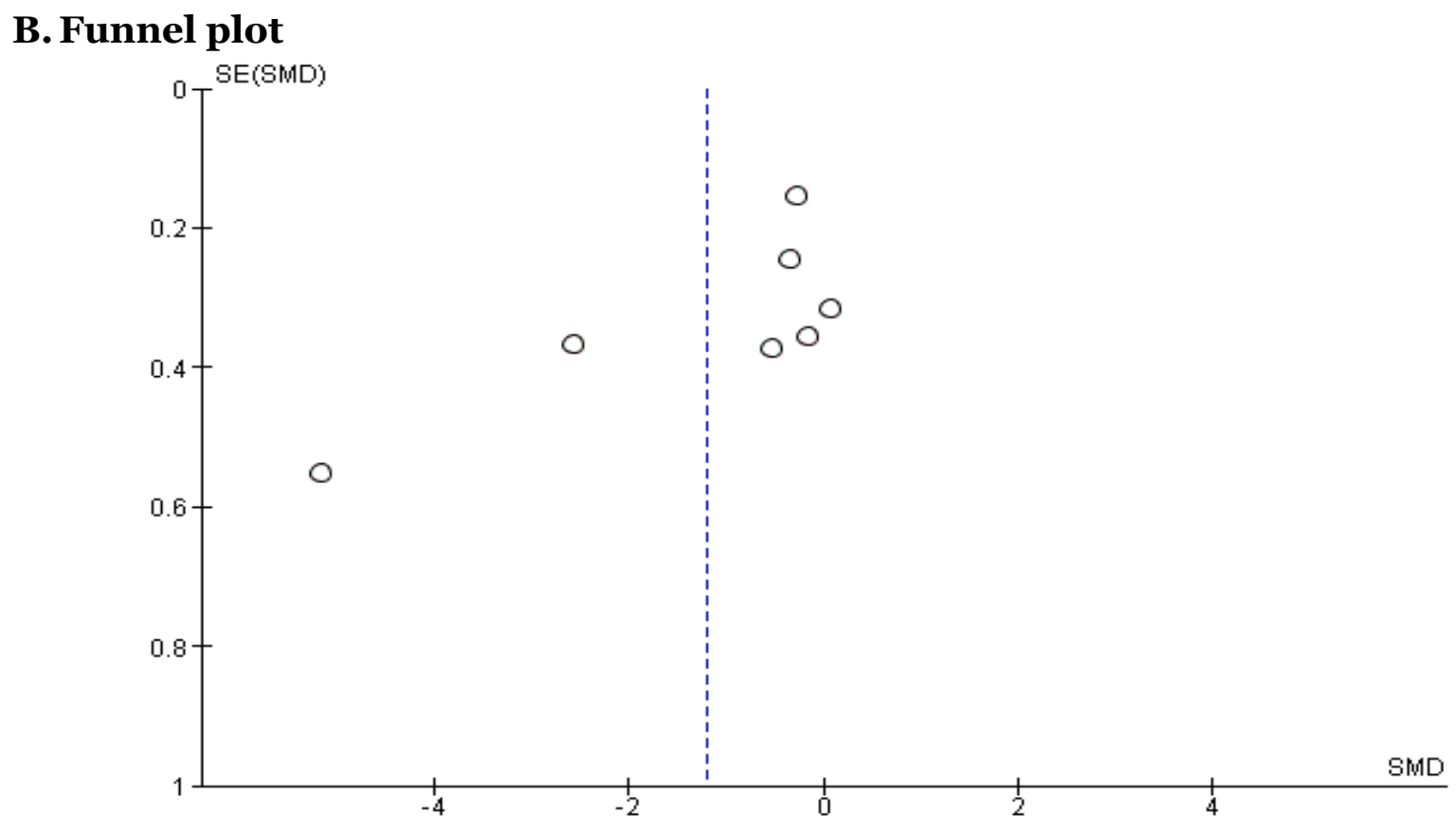

Figure 4. Funnel plot of the effect of kinesio tape on the reduction of pain in patients with carpal tunnel syndrome

Based on the results of the analysis in the figure above, it can be seen that as many as seven articles reported that giving Kinesio Tape was one way that affected the reduction of pain in patients with Carpal Tunnel Syndrome. Based on the results of the analysis, there was high heterogeneity between experiments (I2=94\%; $\mathrm{p}<0.001)$ so it used the Random Effect Model (REM).

The funnel plot (figure 4) shows a publication bias which is marked by the asymmetry of the right and left plots where the plot on the right side has five plots while on the left side has two plots, so they are not symmetrical with each other and do not form an inverted funnel. The left plot has a standard error of $>0.5$, while the right plot has a standard error of $>0.4$. Bias also occurred from the imbalance between the distances among studies on both the right and left of the funnel plot.

\section{DISCUSSION}

This systematic and meta-analysis study raised the theme of the effect of Kinesio
Tape on the Reduction of Pain in Patients with Carpal Tunnel Syndrome. This study discussed data about the influence of Kinesio Tape which was considered important because of its scarcity. The number of relevant and accessible studies published were still limited and also had data access problems (data duplication) (Murti, 2018).

The reduction in pain with the administration of Kinesio tapes was due to decreased neural activation, increased blood circulation to the fascia and soft tissues. It could restore fascial function through normalizing muscle tension and improving muscle function (Mohamed et al, 2016).

Based on the theory of control gates, KT could reduce pain through feedback on large diameter afferent nerve fibers and cause reduced stimulation from small-diameter nerve fibers which could cause pain (Tantawy and Kamel, 2015).

The reduction of pain based on KT gate control theory can stimulate cutaneous mechanoreceptors that can activate large diameter afferent nerve fiber impulses and 
cause reduced stimulation of small-diameter nerve fibers which is the cause of pain.

Furthermore, the administration of Kinesio taping aimed to relax muscles. Kinesio taping which was applied througha pull on the skin could cause the fascia to return to its normal position. The stretching of the skin layers could lead to increasing subcutaneous and lymphatic blood flow, it was believed to repair and collect the fascial tissue to return to the anatomical position or the desired position so that it could reduce pain and pressure on the tissue under the fascia (O'Sullivan and Bird, 2011).

The Systematic review and meta-analysis technique in this study was carried out to increase the generalizability of the findings and obtain convincing conclusions from various similar study results regarding the Effect of Kinesio Tape on The Reduction of Pain in Patients with Carpal Tunnel Syndrome.

The Results of a meta-analysis of seven articles regarding $\mathrm{KT}$ administration on the reduction of pain in CTS cases. Based on the results of the analysis, there was high heterogeneity between experiments ( $\left.\mathrm{I}^{2}=94 \% ; \mathrm{p}<0.001\right)$ so it used the Random Effect Model (REM). The administration of KT was able to reduce pain in CTS, statistically very significant (Standardized Mean Difference -1.21; CI 95\% -2.14 to -0.28; $\mathrm{P}<0.01)$.

A study conducted by Kosery et al, (2012) showed that Kinesio taping was very effective, efficient, cheap, light, safe, and harmless in CTS cases. The elastic properties of Kinesio taping also created gentle massage with movement, changes in pressure, and movement of the skin could open and close the initial lymphatic vessels, and kinesio taping on the lymphatic surface could stimulate edema movement, the reduction of edema removed heat and chemi- cals in the tissue, improved circulation and reduced trigger points (Ardella, 2013).

This study is in line with the study performed by Nagib et al, (2017) that the distribution of KT in CTS cases could affect hand pain and function with BCTQ. Moreover, the study conducted by Park et al (2017), Kaya (2015), Janusz (2016), and Ali et al (2013) stated that Kinesio tape was effective in reducing pain in CTS cases.

\section{AUTHOR CONTRIBUTION}

Cahyo was the main researcher who selected topics, explored, and collected data of the study. Didik Gunawan Tamtomo and Hanung Prastya played a role in analyzing data and reviewing documents of the study.

\section{CONFLICT OF INTEREST}

There was no conflict of interest in this study.

\section{FUNDING AND SPONSORSHIP}

This study used private funds from the principal investigator.

\section{ACKNOWLEDGEMENT}

We would like to thank the database providers, PubMed, ScienceDirect, and Google Scholar.

\section{REFERENCE}

Aroori S, Spence RAJ(2008). Carpal Tunnel Syndrome. Ulster Med J. 77(1): 617.http://www.ncbi.nlm.nih.gov/pmc/articles/pmc2397020/.

Ashworth N (2009). Clinical Evidence Carpal Tunnel Syndrome. Edmonton Canada: Associate Profesor University of Alberta.https://www.ncbi.nlm.nih.gov/pubmed/21718565.

Biondi-Zoccai G, Lotrionte M, Landoni G, Modena MG (2011). The trough guide to systematic reviews and meta-analysis. HSR Proc intensive CareCardio- 
Setiawan et al./ The Effect of Kinesio Taping on Pain in Patients with Carpal Tunnel Syndrome

vascAnesth, 3: 161-173.http://www.ncbi.nlm.nih.gov/pmc/articles/pmc3484632 .

Ciolac EG, Mantuani SS, NeivaCM, Verardi C, Pessoa-Filho DM, Pimenta L (2015). Rating of perceived exertion as a tool for prescribing and self regulating interval training: A pilot study. J Sport and Health Sci, 32: 103-108. doi: $10.5604 / 20831862.1134312$.

Cochrane (2014). RevMan 5.3 User Guide. The Cochrane Collaboration.

Dale AM et al. (2013). Prevalence and incidence of carpal tunnel syndrome in US working populations: pooled analysis of six prospective studies. USA: Scand. J. Work Environ Health. 1-11. doi: 10.5271/sjweh.3351.

Dennerlein JT, Johnson PW (2006). Changes In Upper Extremity Biomechanics Across Different Positions In A Computer Workstation Ergonomics. JAMA. 49(45): 354-375. doi:10.1080/00140130600811620.

Dilek B, Batmaz I, Sarıyldız MA, et al. (2016).Kinesio taping in patients with lateral epicondylitis. J Back Musculoskelet Rehabil. 29: 853-8.doi: 10.3233/BMR-160701.

Geler Külcü D, Bursali C, AktaşI, Bozkurt Alp S,ÜnlüÖzkan F, Akpinar P (2016). Kinesiotaping as an alternative treatment method for carpal tunnel syndrome. Turk J Med Sci; 46: 1042-9. doi: 10.3906/sag-1503-4.

Haidich AB (2010). Meta-analysis in medical research. Hippokratia. doi: https://doi.org/10.5005/jp/books/10519.

Ibrahim I, Khan WS, Goddard N, Smitham P(2012). Carpal Tunnel Syndrome: A Review of the Recent Literature. UK: Open Orthop J. 6(1): 69-76. doi: 10.2174/1874325001206010069.

Janusz, K (2016). Kinesio Taping In Conservative Treatment Of Mild-To-Mo- derate Cases Of Carpal Tunnel Syndrome Kinesio Taping W Leczeniu Zachowawczym Łagodnego I Umiarkowanego Przebiegu Zespołu Cieśni Nadgarstka. 6(9): 604-609. doi: 10.5281/zenodo.155060.

Karabay N, Kayalar M, Ada S (2013). Sonographic assessment of transverse carpal ligament after open surgical release of the carpal tunnel. Turkey: Acta Orthopaedica et Traumatologica Turcica. 47(2): 73-38. doi: 10.3944/aott.2013.2890.

Kase K, Wallis J, Kase T (2013). Clinical Therapeutic Applications of the Kinesio Taping Method 2nd Edition. Tokyo: Ken Ikai. Retrieved from: https://www.amazon.com/ClinicalTherapeutic-Applications-KinesioTaping/dp/098903240X.

Macleod MR, Tanriver-Ayder E, Hair K, Sena E (2019). Design of MetaAnalysis Studies. In J. E. Barrett (Ed.), Good Research Practice in NonClinical Pharmacology and Biomedicine. Cham, Switzerland: SpringerOpen. Retrieved from: https://link.springer.com/chapter/10.1007/164_2019_2 89.

Mikolajewicz N, Komarova SV (2019). Meta-analysis methodology for basic research: A practical guide. Frontiers in Physiology. doi:https://doi.org/10.3389/fphys.2019.00203.

Morris D, Jones D, Ryan H, Ryan CG (2013). The clinical effects of Kinesio Tex taping: A systematic review. Physiother Theory Pract; 29(4): 259-70. doi: 10.3109/09593985.2012.731675.

Mitranun W, Deerochanawong C, Tanaka H, Suksom D (2014). Continuous vs interval training on glycemic control and macro and microvascular reactivity in type 2 diabetic patients.Med 
Setiawan et al./ The Effect of Kinesio Taping on Pain in Patients with Carpal Tunnel Syndrome

\&Sci Sports Exerc, 24: E69-E76. doi: 10.1111/sms.12112.

Murti B (2018). Prinsip dan Metode Riset Epidemiologi (5th ed). Surakarta: Program Studi Ilmu Kesehatan Masyarakat, Program Pascasarjana, Universitas Sebelas Maret.

Newington L, Harris EC, Walker-Bone K (2015). Carpal Tunnel Syndrome and Work. Best Pract Res Clin Rheumatol. 29(3): 440-453. doi: 10.1016/j.berh.2015.04.026.

Sumartiningtyas, Wulandari S (2018). Pengaruh kinesio taping dan mobilisasi saraf terhadap penurunan nyeri pada kasus carpal tunnel syndrome. Surakarta: Universitas Muhammadiyah Surakarta. Retrieved from: http://eprints.ums.ac.id/id/eprint/66222.

Wu WT, Hong CZ, Chou LW (2015). The Kinesio Taping Method for Myofascial Pain Control. Evidence-Based Complementary and Alternative Medicine (2015): 1-9. doi: 10.1155/2015/950519. 